\title{
NE BIS IN IDEM MATERIAL Y PROCESAL
}

Miguel Díaz y García Conlledo

Catedrático de Derecho Penal Universidad de León (España)

\section{Especial referencia al cambio de jurisprudencia constitucional en España*}

\section{Introducción}

L

a prohibición de incurrir en bis in idem (dos veces sobre lo mismo) o principio non o ne bis in idem se entiende, en líneas generales y prescindiendo ahora de detalles, como la interdicción de sancionar repetidamente a un sujeto por el mismo hecho. Constituye un principio general del Derecho, ha sido reconocido por diversa normativa internacional (aunque con matices, por ejemplo, respecto de lo que podríamos llamar ne bis in idem internacional, es decir, referido a la imposibilidad de doble sanción o doble proceso en diferentes Estados, que no se reconoce en términos absolutos en esa normativa ${ }^{1}$ ), en la normativa interna de muchos países, y se recoge expresamente en algunas leyes españolas (así, en el art. 133 de la Ley de la Ley de Régimen Jurídico de las Administraciones Públicas y Procedimiento Administrativo Común (LRJAPYPAC) y en el art. 5.1 del Reglamento para el ejercicio de la Potestad Sancionadora).

Al contrario de lo que sucede en algunos países, como Alemania, la Constitución española no menciona expresamente la prohibición de incurrir en bis in idem o, si se prefiere, el derecho de los ciudadanos a no ser sancionados repetidamente. No obstante, el Tribunal Constitucional español le viene atribuyendo rango constitucional

\footnotetext{
* Este trabajo se presentó, en sus líneas esenciales, como ponencia en el XI Congreso de Estudiantes de Derecho Penal 2004: Constitución y Derecho Penal (24, 25 y 26 de marzo de 2004) en la Universidad de Barcelona, el 26 de marzo de 2004, bajo el título Vertientes procesal y penal y de las garantías constitucionales: ne bis in idem procesal y material. No fue pensado, en principio, como artículo, lo que explica la ausencia de aparato bibliográfico y la omisión de tratamiento de algunos aspectos y la simplificación de algunas exposiciones y argumentaciones. Sin embargo, se ha revisado y completado para su publicación. El trabajo se ha beneficiado de forma más o menos directa de la financiación de los Proyectos de investigación BJU 2001-0121 (Ministerio de Ciencia y Tecnología, parcialmente fondos FEDER), LE 55/02 (Junta de Castilla y León), uno financiado por la Excma. Diputación Provincial de León, SEJ2004-00062, y se enmarca también en otro de la Junta de Castilla y León cuya financiación está pendiente de resolver, de los que soy investigador principal.

1 Aunque no podré detenerme aquí en esta cuestión, resulta muy importante desde la perspectiva del Derecho español, en relación con otros países de la Comunidad Europea la reciente Sentencia del Tribunal Supremo (STS) de 22-12-2003 (RJ 2004/16, ponente: BACIGALUPO ZAPATER), que, basándose en buena medida en la argumentación de la segunda de las STC de que nos ocuparemos en este trabajo, viene a reconocer la vigencia de un ne bis in idem internacional (matizado).
} 
en múltiples resoluciones a partir de la Sentencia del Tribunal Constitucional (STC) 2/1981, de 30 de enero, en conexión con los principios de legalidad y tipicidad del art. 25.1 de la Constitución Española (CE). Puede decirse que el fundamento general de la prohibición es la protección de la seguridad jurídica (art. 9.3 CE), si bien las distintas facetas del ne bis in idem concretan el fundamento en los principios de legalidad y proporcionalidad (ne bis in idem material) y en el de tutela judicial efectiva sin indefensión (art. 24.1 CE, al que se añade a veces el derecho a un proceso con garantías del número 2 del mismo artículo) (ne bis in idem procesal), como veremos enseguida.

Tras esta sucinta introducción, señalaré qué entiende el Tribunal Constitucional (TC) (y, de una u otra forma, la doctrina) por las facetas material y procesal del ne bis in idem, para, a continuación, ilustrar la discusión con dos importantes STC, de signo muy distinto.

\section{Ne bis in idem material o sustantivo}

Se entiende por tal la prohibición de doble (o múltiple) sanción cuando exista en el caso una triple identidad de sujeto, de hecho y de fundamento (a excepción de los supuestos en que exista una "relación de sujeción especial" disciplinaria, de los que aquí prescindiremos). Si el sujeto, el hecho y el fundamento por el que se castiga son los mismos, queda vedada la doble sanción en el mismo orden, administrativo o penal, y en los dos órdenes, concurrencia de sanciones administrativas y penales, con independencia, en el primer caso, de que ello suceda en uno o en varios procesos.

La seguridad jurídica fundamentaría esta prohibición (o derecho, según la perspectiva que se adopte), pero, más en concreto, se hallaría ligada a los principios del legalidad (y al conexo de tipicidad) y proporcionalidad. Efectivamente, la garantía que supone para el ciudadano el principio de legalidad se vería vulnerada si, por ser posible la doble sanción de su hecho, no pudiera calcular de antemano las consecuencias jurídicas del mismo (la sanción establecida por unos hechos no sería la finalmente impuesta si se admite la doble sanción). Por otro lado, la proporcionalidad en el castigo que prevé cada norma sancionadora se vería desbordada si se produce una acumulación de sanciones en las circunstancias señaladas: la sanción no sería proporcional a la gravedad del hecho (y, en su caso, a la culpabilidad del sujeto), sino mayor o más grave.

\section{Ne bis in idem procesal}

Menos unívoco es el significado que se ha otorgado (en las propias STC y en la doctrina) a la vertiente llamada procesal del principio. 
Así, se habla de la prohibición de ser sometido a un doble proceso en sentido estricto. Ello se fundamentaría nuevamente en la protección de la seguridad jurídica, pues el ciudadano no puede estar en una situación de permanente inseguridad, especialmente una vez resuelto un procedimiento, derivada de la posibilidad de que se abra otro por igual causa. Pero, más en concreto, esta faceta se fundamentaría en el derecho a la tutela judicial efectiva sin indefensión (y a un proceso con garantías), pues la misma no sería efectiva si siempre se puede "reabrir" o "duplicar" la causa. En este sentido estricto se proscribiría no sólo la vulneración de la cosa juzgada, sino la existencia de dos procesos (especialmente penales) sobre idéntico asunto. Una consecuencia de la radical vigencia de este principio en el proceso penal la constituiría la limitación de las posibilidades de las partes acusadoras de recurrir sentencias penales absolutorias a los supuestos en que se hayan producido defectos en el proceso vulneradores de reglas esenciales del mismo, esto es, falta de respeto a las garantías básicas del debido proceso.

Pero esta faceta se extiende más allá de la prohibición de doble proceso en sentido estricto y de ella se han derivado, entre otras, las siguientes consecuencias, que son las que más nos van a interesar aquí: subordinación de la Administración a la Autoridad Judicial, con la necesidad de que aquélla esté sometida en su actuación a los procedentes recursos judiciales, de que respete la cosa juzgada, proscripción de la posibilidad de determinación de los hechos diferente en diversos procesos (debiendo la Administración respetar los fijados por el órgano jurisdiccional cuando actúe con posterioridad a éste), prohibición de sanción de los mismos hechos por dos autoridades del mismo orden, imposibilidad de esgrimir el principio ne bis in idem para algo distinto de la paralización del nuevo ejercicio de la potestad sancionadora o la anulación de la segunda resolución (no la primera), imposibilidad de que la Administración desarrolle actuaciones o procedimientos sobre hechos posiblemente constitutivos de delito o falta, debiendo abstenerse en tanto no resuelva la Autoridad judicial (así se recoge en el art. 133 LRJAPYPAC). Importante es la declaración de la primera de las STC en que nos vamos a fijar de que la subordinación de la Administración a la Jurisdicción penal y la prioridad de ésta no puede prevalecer frente a la faceta materia del ne bis in idem, algo contradicho claramente en la segunda.

\section{Recientes Sentencias del Tribunal Constitucional claves en la materia}

\section{a) STC 177/1999, de 11 de octubre}

La Sentencia fue dictada por la Sala Primera del TC, siendo ponente, el Magistrado Sr. D. Pablo García Manzano. A partir de una inspección (febrero 1990) 
realizada por la Junta de Aguas de la Generalitat de Catalunya, la Junta incoa expediente administrativo (marzo 1990) a la sociedad IRM Lloreda S.A., dedicada al recubrimiento de metales, por presunta falta grave por los vertidos que realiza de forma inadecuada al río Congost la citada empresa. Finalmente, tras diversas actuaciones, en noviembre de 1990 se impone a la empresa una sanción de un millón de pesetas por falta menos grave.

Aproximadamente un mes antes, la Junta de Aguas, había remitido un oficio a la Policía Judicial, entre otras cosas, por si los hechos podían ser constitutivos de delito.

En febrero de 1991, la Fiscalía interpone querella contra directivos de la empresa, que terminó con la condena, en marzo de 1991, por parte del Juzgado de lo Penal no 22 de Barcelona a José María Ll., consejero delegado y técnico que dirigía, gestionaba y controlaba la empresa, como autor del delito contra el medio ambiente del art. 347 bis CP 1944/73, a dos meses de arresto mayor, accesorias legales, y multa de un millón de pesetas, pero declarando expresamente que del pago de la multa se descontará lo ya pagado en vía administrativa como consecuencia de la sanción recibida en dicha vía.

Frente a la alegación de bis in idem, señala que debe prevalecer la actuación jurisdiccional y que lo único que puede hacerse es la compensación citada. La Sección $10^{\mathrm{a}}$ de la Audiencia Provincial (AP) de Barcelona confirma en octubre de 1994 la sentencia.

El condenado recurre en amparo, alegando vulneración de la prohibición constitucional de incurrir en bis in idem. La STC 177/1999 concede este amparo, pues entiende que las dos resoluciones judiciales (Juzgado de lo Penal y de la AP) conculcan el derecho a la legalidad penal y sancionadora, en su vertiente de no ser doblemente sancionado por los mismos hechos (art. 25.1 CE), entendiendo que, irrogada una sanción, aunque sea administrativa, no se puede superponer o adicionar otra distinta sin vulnerar el citado derecho, siempre que concurran identidad de sujeto, hecho y fundamento de la sanción, como era el caso según la sentencia.

A la sentencia se opone un voto particular discrepante conjunto del entonces Presidente del TC, Sr. D. Pedro Cruz Villalón, y de la Magistrada Dña. M ${ }^{a}$ Emilia Casas Baamonde, que estima que no se dio la triple identidad, incidiendo sobre todo en lo que al fundamento se refiere, y que debe prevalecer la sanción penal, señalando que la solución de la sentencia dando preferencia a la primera sanción, es decir, la administrativa, "es una solución ajena a la norma constitucional".

\section{b) STC $2 / 2003$, de 16 de enero}

Esta sentencia, cuya ponente es la Magistrada Sra. Dña. María Emilia Casas Baamonde, es decir, una de las firmantes del voto particular a la anterior (y poste- 
riormente, no en el momento de dictar la sentencia, Presidenta del TC). Por ello no extraña que cambie radicalmente la doctrina constitucional establecida en la que acabamos de citar, como expresamente señala la sentencia, por la que es dictada por el pleno (también cambia la doctrina de la STC 152/2001, de 2 de julio). No extraña por ello tampoco que a esta nueva STC se formule un voto particular por el Magistrado Sr. D. Pablo García Manzano, precisamente el ponente de la STC 177/1999.

Los hechos iniciales fueron: en abril de 1997, José, con antecedentes por delitos contra la seguridad del tráfico, en concreto, conducción bajo influencia de bebidas alcohólicas, conducía su coche con sus facultades disminuidas por haber ingerido un exceso de alcohol; le detiene la Guardia Civil por ir muy despacio, en zig-zag e invadiendo el carril contrario. Ante los diferentes síntomas de ebriedad que presentaba, se le somete a las correspondientes pruebas de detección alcohólica, resultando positivas con una tasa muy superior a la permitida legalmente (comprobada en aire espirado y en sangre).

Los hechos dan lugar a incoación de diligencias previas ese mes y la denuncia de la Guardia Civil entra en agosto, con copia del Auto de incoación de diligencias previas, en la Jefatura Provincial de Tráfico, que inicia expediente, lo que se comunica, al igual que la propuesta de resolución, al denunciado por edictos. La resolución sancionadora se le comunica personalmente en marzo de 1998 al sancionado, que el mes siguiente interpone recurso ordinario alegando la excepción de cosa juzgada por estar sustanciándose un procedimiento penal por los mismos hechos. Aunque la Dirección General de Tráfico estima parcialmente el recurso en lo relativo a la duración de la suspensión del permiso de conducir, lo que aquí nos interesa es que señala erróneamente que se ha dictado resolución penal absolutoria por no haberse constatado la existencia de delito o falta. El sancionado interpone recurso contencioso-administrativo, pero se le da por desistido del mismo en diciembre de 1998.

El proceso penal se sigue sin que el acusado notifique la existencia del expediente administrativo y sin resolución hasta el juicio oral, donde plantea como excepción previa la de cosa juzgada. El Juzgado de lo Penal de Ferrol desestima la cuestión por la preferencia de la jurisdicción penal, no aprecia por tanto bis in idem y condena por un delito contra la seguridad del tráfico del art. 379 CP en sentencia de 29 de junio de 1999. El condenado denuncia la sentencia, alegando, entre otras cosas, vulneración del ne bis in idem, recurso que desestima la AP de La Coruña, que señala que hubo error en el expediente administrativo que es preferente la vía penal, ordena que se deje sin efecto cualquier consecuencia posterior del expediente, y ordena que se descuente en ejecución 
de sentencia la multa ya satisfecha y la duración de la privación del carnet de conducir.

El condenado recurre al TC en amparo, alegando, con diversos argumentos y cita de doctrina jurisprudencia del TC, entre otras, la de la STC 177/1994, vulneración del principio ne bis in idem, constitucionalmente reconocido.

La amplia y minuciosa STC que ahora comentamos aborda numerosas e importantes cuestiones relacionadas con el mencionado principio, en concreto la del momento del proceso penal en que se puede invocar la vulneración del derecho fundamental alegado, entendiendo que es el comienzo del juicio oral; la competencia del TC para revisar la triple identidad de sujeto, hecho y fundamento que delimita el contenido del derecho fundamental; la doctrina sobre reiteración punitiva, entendiendo que no basta la mera declaración de imposición de la sanción, sino que la vulneración de la vertiente material del derecho requiere la efectiva reiteración sancionadora; y finalmente la cuestión de "la relevancia del órgano sancionador que conoce los hechos en primer lugar, afirmando la competencia exclusiva de la jurisdicción penal para sancionar en estos casos de concurrencia aparente de infracciones administrativa y penal". Por todo ello, desestima el amparo.

De algunos de estos pronunciamientos nos ocuparemos a continuación.

El voto particular descrepante del Magistrado Sr. D. Pablo García Manzano, ponente de la STC 177/1999, aunque advierte que reconoce el esfuerzo por rectificar lo que la STC considera erróneo en ésa y la otra STC citadas y por ahondar en el debatido problema del ne bis in idem, "en su más paradigmática y tradicional formulación: duplicidad punitiva de sanciones administrativa y penal", considera que el amparo debería haberse otorgado.

Discrepa de la competencia del TC para revisar la triple identidad, cree que no se puede acudir a la idea de la compensación en la pena para entender no vulnerado el principio cuando se ha afirmado la triple identidad (y detalla problemas de esa compensación), pretende limitar el alcance de la prevalencia de la jurisdicción penal, y, en definitiva, aprecia bis in idem porque no se pueden cargar al administrado los errores de la tramitación de los expedientes administrativos. Considera que el amparo debería haberse otorgado.

\section{Consideraciones en torno al ne bis in idem material}

Reitero que no es posible aquí detenernos en todas las cuestiones que plantean al respecto las dos STC mencionadas, por lo que seleccionaremos algunas de las principales. 


\section{a) La supuesta incompetencia del TC para revisar la apreciación de identidad o falta de identidad de sujeto, hecho y fundamento}

En la STC 177/1999 (como en algunas otras, aunque quizá no de forma tan clara) se señala que el TC carece de la competencia para revisar la apreciación de identidad o falta de identidad de sujeto, hecho y fundamento, pues ello supondría una revisión de la determinación de los hechos efectuada por el órgano jurisdiccional penal que está vedada al TC por el art. 44.1 b de la Ley Orgánica que lo regula. Sin embargo, no es esto lo que sostienen otras resoluciones del TC. Y muy claramente la STC 2/2003 (en contra, el voto particular a la misma), según la cual "esta afirmación no puede compartirse, pues la triple identidad constituye el presupuesto de aplicación de la interdicción constitucional de incurrir en 'bis in idem', sea éste sustantivo o procesal, y delimita el contenido de los derechos fundamentales reconocidos en el art. 25.1 CE, ya que éstos no impiden la concurrencia de cualesquiera sanciones y procedimientos sancionadores, ni siquiera si éstos tienen por objeto los mismos hechos, sino que estos derechos fundamentales consisten precisamente en no padecer una doble sanción y en no ser sometido a un doble procedimiento punitivo, por los mismos hechos y con el mismo fundamento", si bien señala que en este análisis el TC deberá partir de los hechos admitidos como probados y de las calificaciones de los mismos realizadas por el órgano jurisdiccional correspondiente.

En definitiva, como con razón se ha señalado también en la doctrina, una cosa es que el TC no pueda modificar la determinación de hechos y su calificación jurídica ni entrar en las diversas interpretaciones posibles de preceptos legales y otra bien distinta que, partiendo de ellos, no pueda valorarlos desde la perspectiva del supuesto derecho fundamental vulnerado. Me parece claro por tanto, dicho simplificadamente, que el TC puede y debe entrar a analizar la existencia o inexistencia de la triple identidad, respetando los hechos y sus calificaciones, pues aquélla es un dato muy relevante para la determinación de si se ha vulnerado el derecho a no ser sometido a doble sanción (y/o proceso).

\section{b) La triple identidad}

Pasamos ahora a analizar los tres términos de la señalada triple identidad.

\section{$\left.b_{1}\right)$ De sujeto}

El requisito de identidad de sujeto significa, como resulta evidente, que, para que pueda preciarse un bis in idem, la doble sanción ha de haber recaído sobre la misma persona. Esto no plantea ningún problema en el supuesto de la STC 2/2003, pues es obvio que es la misma persona física la que es sometida al procedimiento adminis- 
trativo sancionador y al proceso penal y recibe sanción en ambos. Más problemático es el caso de la STC 177/1999, pues en ella la actuación y la multa administrativa se dirige contra la empresa, esto es, contra una persona jurídica, mientras que la pena se impone a su consejero delegado, es decir, a una persona física.

Partiendo de la, en mi opinión, correcta comprensión de la irresponsabilidad penal de las personas jurídicas y de que, por lo tanto, ellas no son destinatarios de la norma jurídicopenal, algunos autores, como CORCOY BIDASOLO/GALLEGO SOLER, entienden que en casos como el de la STC comentada no se produce identidad de sujetos. Personalmente, sin embargo, no estoy de acuerdo, como otro sector doctrinal, con esta posición. Los propios autores citados matizan que el condenado penalmente materialmente controlaba toda la actividad empresarial en una empresa pequeña y que, por ello, probablemente se podría decir que era también el destinatario de la norma administrativa regulativa y sujeto de las dos sanciones, si bien señalan que tal apreciación chocaría con el obstáculo infranqueable de que formalmente se ha sancionado a dos sujetos distintos y que las particularidades del caso no serían extrapolables a otros con carácter general.

En mi opinión, como señala, por ejemplo, PÉREZ MANZANO, la infracción de cualquier norma requiere siempre la actuación de una persona física e incluso cuando, como en el orden administrativo (entre otros), se reconoce la capacidad de la persona jurídica de infringir la norma, la misma emana de la persona física. Por lo tanto, la imposición de sanción a la persona jurídica y a la persona física que actúa por ella supone la presencia del primer requisito de la triple identidad, la de sujeto, si bien habría que matizar aquí algunos aspectos relativos a la necesidad de constatar que la sanción a la persona jurídica afecte a la física para poder apreciar esta identidad. En todo caso, nada obliga a adoptar una perspectiva formal en el análisis de esta identidad.

\section{$b_{2}$ ) De hecho}

La identidad de hecho u objeto se dará cuando los hechos sancionados sean los mismos. Ahora bien, en su constatación puede adoptarse una perspectiva meramente naturalista u otra denominada habitualmente normativa. Desde la primera, lo que se compara son los acontecimientos naturales, es decir, el suceso de la vida real que dio lugar a las sanciones. En los casos de las STC a que nos venimos refiriendo, desde esta perspectiva, no cabe duda de que los hechos objeto de las sanciones administrativa y penal en los supuestos que dieron lugar a las STC comentadas (vertidos al río y conducción habiendo ingerido alcohol) fueron los mismos. Sin embargo, creo que no es ésta la perspectiva que hay que adoptar en el análisis de la identidad de hechos. 
Desde la perspectiva llamada habitualmente normativa que defiende la mayoría de la doctrina, para la comparación, entre los hechos naturales acaecidos han de seleccionarse aquellas partes del suceso relevantes para constituir la infracción administrativa y el delito o falta de que se trate, es decir, se han de comparar los hechos desde la perspectiva de las normas tipificadoras de las correspondientes infracciones. Lo dicho no debe hacer creer que la comparación es entre normas o contenido de normas, pues entonces esta identidad (o falta de ella) se confundiría en gran medida con la de fundamento de la sanción (lo que me da la impresión sucede, al menos en parte, en algunos pronunciamientos). La comparación es entre elementos fácticos del suceso natural, pero sin tener en cuenta aquellos que sean irrelevantes para integrar cada una de las infracciones sancionadas.

Desde esta perspectiva, en relación con la STC 177/1999, autores como CORCOY/GALLEGO niegan la existencia de identidad de hecho u objeto entre los que dieron lugar a la sanción administrativa y los que fundamentaron la pena. Y la misma idea se manifiesta (aunque sin referirse expresamente a la falta de identidad de hecho, sino sólo de fundamento) en el voto particular a la STC mencionada. Así, se señala que el art. 108 f) de la Ley de Aguas tipifica, sin más, como infracción administrativa los vertidos que puedan deteriorar la calidad del agua efectuados sin contar con la preceptiva autorización, y el art. 316 g) del Reglamento del Dominio Público Hidráulico, en relación con su art. 14, considera infracción administrativa menos grave la misma conducta, siempre que los daños al dominio público no superen las 500.000 pts. (como calificó la Junta de Aguas de la Generalitat de Catalunya). Por su parte, el tipo penal (tanto el actual -art. 325- como el vigente en el momento de los hechos -art. 347 bis CP 1944/73-, aunque no de forma idéntica) exige peligro de grave perjuicio para el equilibrio de los sistemas naturales o, en su caso, la salud de las personas (antes ésta o las condiciones de vida animal, bosques, espacios naturales o plantaciones útiles). Por lo tanto, para la infracción administrativa esta faceta de peligro de los hechos acaecidos no se toma en cuenta (basta el vertido, sin que ello signifique que el interés en la protección ambiental esté absolutamente ausente, como más adelante diré), mientras que sí ha de tenerse en cuenta desde la perspectiva de la infracción penal.

Pues bien, en mi opinión, aun estando plenamente de acuerdo con la contemplación "normativa" de los hechos y con que, obviamente, desde esta perspectiva no son exactamente los mismos los que hay que tener en cuenta como objeto de cada una de las sanciones, y, por lo tanto, no se puede hablar en general de identidad de hecho u objeto, discrepo de las opiniones citadas en cuanto a que no se dé la identidad de hecho relevante a efectos de ne bis in idem. Pues el que en la 
determinación de la existencia de infracción penal se tengan en cuenta facetas de los hechos añadidas a las tomadas en consideración para constatar la existencia de infracción administrativa no significa que todas las contempladas en relación con ésta no lo sean también en relación con la infracción administrativa. De hecho, el vertido es un elemento del tipo penal, pero no sólo ello, sino que la infracción de normas administrativas generales también lo es, de modo que, para decirlo de modo simple, la sanción penal se refiere a los mismos hechos que la administrativa y además a otros, pero, desde luego, a los mismos. Y la sanción administrativa no se refiere a hechos no contemplados por la infracción penal. Por ello, estimo que se dio también la identidad de hecho. Sólo cuando la determinación de cada una de las infracciones requiera tomar en consideración hechos realmente sucedidos que no se toman en consideración en la otra podremos hablar de falta de identidad de hecho u objeto.

Algo similar sucede en lo tocante a los hechos a que se refiere la STC 2/2003, con la diferencia de que en ella parece reconocerse (aunque la referencia es más bien al fundamento) la identidad de hecho, pues, aunque el art. 12.1 de la Ley sobre Tráfico, Circulación de Vehículos a Motor y Seguridad Vial (texto articulado aprobado por Real Decreto Legislativo 339/1990, de 25 de julio) y el art. 20.1 del Reglamento General de Circulación (Real Decreto 13/1992, de 17 de enero, en la redacción que le da el Real Decreto 1333/1994, de 20 de junio) constituyen la infracción administrativa sobre la base de la comprobación de la ingesta de alcohol (u otras sustancias) que produzca determinada tasa de presencia en el cuerpo y, sin embargo, el art. 379 CP exige la constatación de efectiva influencia del consumo de alcohol (u otras sustancias) en la conducción (e indirectamente, por tanto, un peligro al menos abstracto para bienes jurídicos como la vida, la integridad o los bienes de las personas, a través de la llamada seguridad del tráfico), parece que todos los hechos acaecidos tomados en consideración para apreciar la infracción administrativa se tienen en cuenta (y se añaden otros) para la infracción penal. En todo caso, aunque aquí no me puedo detener en ello, esta identidad (que me parece existe) es menos clara que en el supuesto anterior, por la exigencia de una determinada tasa en la infracción administrativa, que no se exige en la penal (aunque lo normal -y así se interpreta- es que, por debajo de esa tasa, no se produzca afectación o influencia en la conducción) o, dicho de otro modo, porque el delito no exige (desde luego no expresamente) infracción administrativa.

\section{$b_{3}$ ) De fundamento}

Lo acabado de decir nos va a permitir abreviar en este punto, pues, aunque hemos hecho referencia a los supuestos que deben ser tenidos en cuenta 
para la apreciación de cada infracción y, por tanto, para comprobar si son los mismos, hemos tenido que referirnos ya en parte al fundamento de una y otra sanción.

No existe un acuerdo total en cuanto a cuál es el fundamento de la sanción que hay que tener en cuenta para comprobar si existe identidad o no: se habla de intereses, bienes jurídicos tutelados, etc. En mi opinión, la referencia al bien jurídico es correcta, pero incompleta. Creo más acertada la postura (PÉREZ MANZANO) que identifica el fundamento con la razón jurídica concreta que sustenta la aplicación de la norma (y, por tanto, la sanción), lo que supone tener en cuenta no el bien jurídico protegido en cada norma en abstracto, sino el concreto bien jurídico y la forma de afectación contemplada como presupuesto de la sanción, es decir, el completo contenido de injusto contemplado en concreto para apreciar cada sanción. A una posición muy similar se puede llegar también, según creo, desde la perspectiva (utilizada por CORCOY/SOLER) de distinguir entre bien jurídico y bien jurídico penal.

Desde esta perspectiva, parece claro que el fundamento de la infracción administrativa y de la penal en los supuestos de las dos STC comentadas no es el mismo. Pues, en una contemplación abstracta, se podría decir que, en el caso de la primera STC, es el medio ambiente el interés o bien jurídico protegido en la infracción administrativa (aunque su carácter es básicamente regulativo) y en el delito medioambiental y, en el de la segunda, ambas infracciones se fundamentan en el interés en proteger la seguridad del tráfico. Pero, en concreto, como correctamente afirma el voto particular a la STC 177/1999, "la apreciación de la existencia del delito requiere la concurrencia de un elemento específico, cifrado en el peligro grave para la salud de las personas o las condiciones de la vida animal, bosques, espacios naturales o plantaciones útiles (se refiere al art. 347 bis CP 1944/73). El interés que salvaguarda la infracción administrativa no es el mismo, operando sobre 'los vertidos de aguas' en orden a la defensa de su calidad o de la de las condiciones de desagüe del cauce receptor a cuyo control destina la exigencia de la 'autorización correspondiente'. La norma penal contiene un elemento que añade desvalor a la infracción administrativa”. De ello deriva este voto particular la inexistencia de identidad de fundamento. Y, con una argumentación similar, pero más completa, llegan a la misma conclusión CORCOY/GALLEGO, advirtiendo que, de seguirse la tesis de la STC 177/1999, que aprecia identidad de fundamento, resultaría que no existe un criterio delimitador entre infracción administrativa y penal, lo que contradice, entre otros (principio de exclusiva protección de bienes jurídicos, en su caso) el carácter de ultima ratio del Derecho penal. 
Nuevamente, estando de acuerdo en la argumentación en cuanto al distinto fundamento de la infracción administrativa y la penal, no puedo coincidir con la consecuencia, pues creo que existe la identidad de fundamento suficiente o relevante para los efectos que aquí interesan. Para empezar, dando la vuelta a la argumentación de CORCOY/GALLEGO, habría que señalar que, de mantenerse a rajatabla la tesis que sustentan en coincidencia con el voto particular señalado, siempre que el legislador haya sido consecuente con el carácter de utima ratio del Derecho penal y, por lo tanto, con las diferencias entre ilícito penal e ilícito administrativo, sería imposible en todo caso la apreciación de identidad de fundamento.

Me parece más bien que lo que hay que comprobar es si el fundamento de la sanción penal abarca todo el de la administrativa y éste no añade nada a aquél, en cuyo caso existirá, a los efectos que aquí interesan, identidad de fundamento, aunque, en términos absolutos o generales no se pudiera hablar de tal. Y, dado que en materia de medio ambiente, el tipo penal incorpora como elemento la infracción administrativa, me parece que se produce la relación acabada de señalar y, por lo tanto, la identidad de fundamento. Frecuentemente se recurre al concurso de leyes o normas para explicar esta relación. Sólo cuando el fundamento de cada una de las infracciones contenga elementos diferentes a las de la otra (o sea, elementos no abarcados por ella) existirá la falta de identidad a los efectos que aquí interesan. Ello explica, por ejemplo, la no oposición al ne bis in idem y la constitucionalidad del castigo (mientras no sea desproporcionado) del concurso ideal de delitos.

Una de las firmantes del voto particular a la STC 177/1999 es, como hemos señalado, la ponente de la STC 2/2003 y parece haber modificado, en mi opinión, acertadamente, su posición en este punto, pues pasa de considerar inexistente la identidad de fundamento en el primer supuesto a apreciarla en el segundo, pese a señalar previamente las claras diferencias entre el ilícito administrativo (que llega a tildar de "formal") y el injusto propio del delito contra la seguridad del tráfico, que exige influencia en la conducción, afectación de las condiciones psicofísicas del sujeto. La razón (que refuerza con cita de jurisprudencia del Tribunal Europeo de Derechos Humanos) sería que "se trata de un caso en que el delito absorbe el total contenido de ilicitud de la infracción administrativa, pues el delito añade a dicho elemento común (scil. conducir habiendo ingerido alcohol, superando determinadas tasas) el riesgo para los bienes jurídicos vida e integridad física, inherente a la conducción realizada por una persona con sus facultades psico-físicas disminuidas, debido a la efectiva influencia del alcohol ingerido". Y eso que, al contrario que en el delito medioambiental, el tipo penal no toma como elemento típico expreso la infracción administrativa. 


\section{c) La insuficiencia de la constatación de la triple identidad para que el principio ne bis in idem se vea vulnerado en su faceta material}

Podría concluirse de lo anterior que, no apreciada por algunos como CORCOY/ GALLEGO la existencia de la triple identidad, deberían entender que en el supuesto no existió vulneración del principio ne bis in idem. Y que, como yo (igual que la STC 2/2003) me he pronunciado a favor de la existencia de la triple identidad, debería coincidir con la STC 177/1999 y afirmar en ese caso la existencia de bis in idem y estar en desacuerdo con el voto particular a esa STC y con la STC 2/2003, y de acuerdo con el voto particular a ésta. Pues bien, nada de ello es exacto.

CORCOY/GALLEGO creen, pese a todo, que existió bis in idem, pero no por la triple identidad (que para ellos no se produjo), sino por "la configuración típica del delito medioambiental como ley penal en blanco, de forma que la existencia de delito requiere de la constatación de una infracción administrativa, por lo que al sancionar en ambos niveles se estará castigando dos veces". Estamos, por lo tanto, de acuerdo, sólo que entiendo que, precisamente, la incorporación al tipo penal de la infracción administrativa fundamenta la identidad (suficiente a nuestros efectos) de hecho y fundamento.

Por otra parte, me parece muy interesante la consideración que incluye la STC 2/2003, al señalar que la afirmación de la triple identidad "no conduce automáticamente a la estimación del amparo, pues se ha de examinar si la interdicción de incurrir en 'bis in idem' constitucionalmente garantizada en el art. 25.1 CE se satisface con una solución como la adoptada en el caso. En particular, hemos de analizar si se ha producido la reiteración punitiva constitucionalmente proscrita", lo que niega, pues considera que, al haber descontado de la cuantía de la multa penal la de la administrativa (como hizo también el órgano jurisdiccional penal correspondiente en el supuesto de la STC 177/1999) y el tiempo de privación administrativa del permiso de conducir de la correspondiente pena, materialmente sólo ha habido una sanción. Además, tiene en cuenta la STC que el órgano penal que enjuició el caso se encontraba, dada la situación normativa existente en España, que no prevé una solución procesal adecuada, en la obligación de condenar penalmente al sujeto, pero con la posibilidad de incurrir con ello en bis in idem, ante el error de la Administración al no haber suspendido el expediente administrativo ante la existencia de actuaciones penales, por lo que la solución adoptada es explicable (podríamos añadir, la mejor de las posibles) (cita nuevamente jurisprudencia del Tribunal Europeo de Derechos Humanos).

En líneas generales, estoy de acuerdo con esta apreciación. De ella, por cierto, ha deducido la STS 22-12-2003 (RJ 2004/16) que el TC ya no fundamenta la 
interdicción de bis in idem en los principios de legalidad y proporcionalidad, sino sólo en éste, en cuanto entiende no vulnerada la prohibición si la pena impuesta es proporcionada. No puedo compartir esta apreciación, pues considero que las vertientes más materiales del principio de legalidad se verían también satisfechas con la solución señalada, pues al sujeto no se le habría impuesto una sanción materialmente distinta de la que desde un principio podía prever si actuaba típicamente.

Sin embargo, aunque en los casos concretos la decisión de los órganos jurisdiccionales penales correspondientes no me parece desacertada, hay que convenir que la superación del bis in idem mediante el expediente de compensación no es la vía más deseable y satisfactoria, entre otras cosas porque no siempre es posible: piénsese en los supuestos en que las sanciones administrativas y las penales no guarden semejanza, como sucede, por ejemplo, si el delito se conmina con pena privativa de libertad, o en aquellos en que se prevé alternativamente a la multa una pena privativa de libertad, en tanto que, para salvar la vigencia del principio ne bis in idem, se produciría una cierta predeterminación hacia la pena de multa (como, con razón, señala el voto particular a la STC 2/2003), o, en fin, en los supuestos en que la multa administrativa supere en cuantía (lo que no significa que la supere en gravedad, ésta es otra cuestión) a la penal.

Ello nos conduce a la necesidad de implementar soluciones más claras y legalmente fijadas para evitar en todo caso que pueda producirse la consecuencia material del bis in idem, combinándolo con una adecuada comprensión de su faceta procesal, a la que paso a referirme.

\section{Consideraciones en torno al ne bis in idem procesal}

Como he señalado, en torno a esta faceta se incluyen diversas consideraciones, no siempre unívocas y claras. Intentaré poner de relieve brevemente algunas que me parecen de especial importancia.

\section{a) La necesidad de no entender algunas de sus facetas en sentido puramen- te formal o cronológico}

Las consecuencias derivadas de la faceta procesal del ne bis in idem no pueden entenderse en un puro sentido formal o cronológico, es decir, admitiendo sin más que, existiendo una primera resolución (o procedimiento), aunque sea administrativa, quede cerrado el paso a otra, aunque sea penal, y pese a que la primera no debiera haberse producido (como es el caso en el supuesto de las dos STC que analizamos). 
Tampoco basta con la apelación a la excepción de cosa juzgada, pues, en puridad, ello conduciría al criterio cronológico, si bien es cierto que la cosa juzgada sólo se predica en sentido estricto en relación con las resoluciones judiciales.

Como vamos a ver a continuación, para determinar sobre todo si tiene sentido la prevalencia del orden penal, hay que acudir a consideraciones materiales.

Pero conviene decir aquí que el criterio cronológico (que, en definitiva o en el resultado, aunque pretendiendo apoyarlo en consideraciones materiales, siguen la STC 177/1999 y el voto particular a la STC 2/2003) plantea problemas muy importantes no sólo en relación con el principio de seguridad jurídica, sino, muy significativamente, con el de igualdad, pues resultaría que, ante hechos iguales, el ciudadano estaría al albur de la existencia o no de errores de la Administración, dependiendo de ello su enjuiciamiento penal o no. Se podría alegar que esa vulneración no es perjudicial para el sujeto concreto, por ser normalmente más benigna la sanción administrativa que la penal, pero supone algo intolerable para el propio ordenamiento jurídico y para la generalidad de los ciudadanos.

\section{b) La prevalencia de la jurisdicción penal}

En relación con la prevalencia de la jurisdicción penal, la STC 2/2003 zanja en principio la cuestión, limitando la prohibición constitucional de doble proceso: "En definitiva, hasta ahora este Tribunal sólo ha reconocido de manera expresa autonomía al derecho a no ser sometido a un doble procedimiento sancionador cuando se trata de un doble proceso penal (...) de modo que la mera coexistencia de procedimientos sancionadores -administrativo y penal- que no ocasiona una doble sanción no ha adquirido relevancia constitucional en el marco de este derecho (...)". Y entiende que en este caso ni el grado de complejidad del procedimiento administrativo ni la naturaleza y magnitud de la sanción que de él deriva pueden equipararse a un proceso penal, por lo que no rige la citada prohibición, máxime cuando la interdicción del doble proceso sólo tiene lugar cuando ambos procesos han sido sustanciados con las debidas garantías (cosa que no sucede aquí en el administrativo, que debió paralizarse). No obstante, deja el TC la puerta abierta a otros supuestos en que sí se produzca la equiparación. Esta argumentación me parece insuficiente. Y, de hecho, el TC, por si acaso, añade, como veremos, algunas otras consideraciones.

Por el contrario, el voto particular a la misma STC sostiene una concepción, en mi opinión, extrema, contraria en relación a la prevalencia de la jurisdicción penal, al señalar que agota sus efectos en una prioridad cronológica de ésta, con la consiguiente paralización de la actuación administrativa, y en el aspecto más 
sustantivo de vinculación de la Administración a los hechos declarados probados en sentencia penal absolutoria. Por ello, el incumplimiento del deber de abstenerse de la Administración (en el caso enjuiciado, por el error de creer que había recaído sentencia absolutoria en el proceso penal) no debe redundar, señala el voto particular, en perjuicio del sujeto, del administrado. Se alinea así con la STC 177/1999, que viene a concebir la proscripción del bis in idem como un derecho de defensa del ciudadano frente al Estado. Con todo lo cual se está dotando, en cierta medida, al argumento cronológico de un contenido material.

Sin embargo, del análisis material que he señalado debe realizarse, se derivan razones suficientes para mantener la prevalencia de la jurisdicción penal y para no excluirla por existir un erróneo pronunciamiento y sanción administrativos previos.

Así, resumiendo los argumentos que aporta un importante sector doctrinal y la propia jurisprudencia del TC, muy significativamente la STC 2/2003, se puede decir que la prevalencia y prioridad de la jurisdicción penal se ancla precisamente en una concepción material del non bis in idem, que parte de la mayor gravedad de las infracciones y sanciones penales, basada en el carácter subsidiario y de ultima ratio del Derecho penal (el DP protege los bienes jurídicos más importantes frente a los más graves ataques a ellos, por lo que sus reacciones punitivas han de ser más graves). La tutela judicial efectiva sólo se desarrolla plenamente en el marco de un proceso penal y no en una actuación administrativa, por mucho que las garantías penales se trasladen, de forma atenuada, al procedimiento administrativo sancionador.

La STC 2/2003, pese a señalar que el TC sólo ha reconocido de modo expreso el derecho a no ser sometido a un doble proceso penal, alude a textos internacionales de derechos humanos para ampliar la prohibición al doble procedimiento sancionador, sea cual sea la naturaleza de éste. Aunque después señala que no se extiende a cualquier procedimiento administrativo, como vimos anteriormente.

Continúa la citada STC afirmando que la prevalencia penal se deriva de la propia regulación legal (general y también el art. 65.1 de la Ley sobre Tráfico, Circulación de Vehículos a Motor y Seguridad Vial), que obliga a la Administración a paralizar el procedimiento, que, en definitiva, es competencia exclusiva de la jurisdicción penal en ese momento. Y, como en el caso la Administración realizó algo que no podía realizar, no tiene sentido anular la segunda resolución (la penal), sino la primera; avalar la resolución administrativa desconocería los principios constitucionales de legalidad sancionadora (art. 21.5 CE) y de competencia 
exclusiva de la jurisdicción penal sobre hechos constitutivos de delito o falta (art. 25.1 en relación con art. 117.3 CE). Por otro lado, la declaración de responsabilidad se produce en un proceso con todas las garantías y presunción de inocencia (art. 24.2 CE), contenido garantista que es menor en el procedimiento administrativo (garantías menores de imparcialidad, especialmente) y, en cuanto a la presunción de inocencia, el TC dice que rige en el procedimiento administrativo, pero no alcanza la publicidad del proceso en el mismo, se admiten como prueba de cargo partes de inspección, etc.

En definitiva, el procedimiento administrativo no puede hacer ceder al penal y no le vincula siquiera en la determinación fáctica.

Como se ha dicho en otras ocasiones, el dar prevalencia a la resolución administrativa conculcaría el reparto de poderes entre los órganos del Estado y la tutela de los bienes jurídicos más importantes frente a ataques graves, propia del Derecho penal.

\section{c) Las posibles soluciones para evitar las consecuencias del doble proceso}

Ahora bien, cuando existen en el "mundo real" ("de facto") dos procedimientos y dos sanciones, aunque no debieran existir, y partiendo de la prevalencia del orden penal, hay que intentar solucionar la situación problemática que se ha generado.

Una solución sería la de la compensación de la sanción administrativa en relación con la pena, pero ya hemos visto sus dificultades. Sólo una regulación legal que estableciera las formas concretas de compensación resultaría algo más satisfactoria, aunque, desde luego, resulta complicado establecer con carácter general esas posibilidades. Por ello, se apunta más bien en otro sentido.

Así, la doctrina (y de ello se hace eco en ocasiones el TC) opta por la nulidad de la actuación y la sanción administrativa, establecida en el art. 62 LRJAPYPAC, bien por la vía de la lesión de derechos y libertades susceptibles de amparo constitucional, bien por la de la apreciación de incompetencia manifiesta del órgano por razón de la materia (supuesto éste especialmente discutible, pues la "materia" parece referirse a otra cosa que el posible carácter delictivo del hecho).

Pese a que el voto particular a la STC 177/1999 señala que el Derecho prevé mecanismos para evitar estas situaciones (la STC 2/2003 no lo afirma de modo tan expreso, pero puede deducirse de ella), la cuestión no es tan sencilla. 
Se proponen diversas soluciones, que llegan incluso a otorgar al Juez penal la capacidad de declarar la nulidad de la resolución administrativa sancionadora, cosa que hoy no puede hacer de oficio y que plantea seguramente problemas desde el punto de vista de la división de poderes.

Una de las propuestas más sugerentes y que me parece acertada en sus líneas generales es la que realizan CORCOY/GALLEGO.

En primer lugar, convendría regular la revisión en vía jurisdiccional contencioso-administrativa de las decisiones equivocadas de la Administración. Así, en el caso de la STC 177/1999, el particular debería haber interpuesto el recurso administrativo ordinario (alzada o reposición) o haber instado de la propia Administración la revisión de oficio de la resolución (art. 102.1 en relación con art. 62.1 a LRJAPYPAC), si bien el que no lo haga no subsana la nulidad de pleno derecho de la actuación administrativa.

El Juez penal debería poder instar a la Administración la citada revisión de oficio de actos nulos. El Juez penal paralizaría el proceso penal en espera del pronunciamiento de la Administración o bien resolvería a la vez que instaba la revisión y la nulidad.

Pero el problema subsistiría si la Administración no insta la revisión o declara correcta la inicial decisión de no paralizar el procedimiento administrativo. En el primer caso, el Juez penal debería poder instar de la jurisdicción contencioso-administrativa un conflicto de jurisdicción para que se pronuncie sobre la actividad de la Administración. En el segundo, probablemente la Administración estaría incurriendo en un delito de prevaricación.

Pero estos autores reconocen que la actual regulación procesal no facilita estas actuaciones.

Por ello parece que urge una reforma legal que imposibilite estas situaciones y que no favorezca, como señalan los autores citados, que una actuación incorrecta de la Administración derive en una ineficacia de las previsiones del Derecho penal (si se anula la sentencia penal) o se corra el riesgo de vulnerar el ne bis in idem por mantener la (necesaria) prevalencia de la jurisdicción penal. Entretanto, considero, con la STC 2/2003, que, mientras sea posible, la solución de la compensación utilizada por los órganos jurisdiccionales penales en los dos casos que nos han servido de guía es la mejor de las soluciones o, si se prefiere, la menos mala, pues preserva el respeto a los contenidos fundamentales de la prohibición de bis in idem material y de su fundamentación en los principios de legalidad y proporcionalidad. 


\section{Otras cuestiones y reflexión final}

No pueden ser abordadas aquí otras cuestiones sin duda importantes en la materia de que nos hemos ocupado, tales como las del momento procedimental adecuado para alegar el derecho, los problemas que plantea en la materia la creciente frecuencia de actuaciones administrativas informales, no inadmisibles con carácter absoluto, pues redundan también en ocasiones en beneficio del ciudadano, etc.

Para concluir, no ocultaré que la posición aquí defendida (y más cercana a la segunda de las STC paradigmáticas en la cuestión analizada) implica una cierta carga para el ciudadano, pero la contraria conculcaría, simplemente para subsanar errores de la Administración, profundos valores de la división de poderes y de la configuración constitucional de la potestad punitiva, e incluso debilitaría la protección (por vía penal) de bienes jurídicos importantes frente a ataques graves a los mismos (en sentido similar CORCOY/GALLEGO y, en la jurisprudencia constitucional, especialmente el voto particular a la STC 177/1999), lo que, en definitiva, sería más perjudicial. 
